\title{
Long-term health and wellbeing of people affected by the 2002 Bali bombing
}

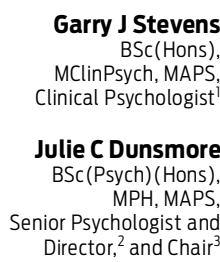

Kingsley E Agho

$\mathrm{BSc}$ (Hons), PhD, MPH

Biostatistician

Melanie R Taylor BSc(Hons), PhD, CPsychol Occupational Psychologist

Alison L Jones

MD, FRCP, FRCPE Toxicologist and Dean

Jason J van Ritten BSc(Hons), GradCertSRM Survey Coordina tor

Beverley Raphae MB BS, MD, FRANZCP Psychiatrist and Professor of Mental Health

1 School of Medicine University of

Western Sydney,

Sydney, NSW.

2 Health Promotion

Department, Northern Sydney Loca Health District.

Sydney, NSW.

3 National Association fo

Loss \& Grief (NSW) Sydney, NSW.

4 Graduate School of Medicine, University of Wollongong

Wollongong. NSW.

5 Centre for Epidemiology

and Evidence, NSW

Ministry of Health

Sydney, NSW.

g.stevens@uws.edu.au

MJA 2013; 198: 273-277 doi: 10.5694/mjal2.11480

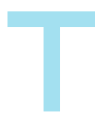

he 2002 Bali bombing resulted in the deaths of over 200 people, including 88 Australians and 35 Indonesians, making it the single worst act of terrorism to have affected either country. ${ }^{1}$ A further 209 people were injured, including 66 Australians who suffered severe burns and complex shrapnel wounds., ${ }^{2,3}$

Terrorism exposure may have significant long-term effects on the mental health and wellbeing of survivors. Post-traumatic stress disorder (PTSD) is the most common psychological condition observed in the aftermath of such events, but it often coexists with depression, functional impairment or substance misuse. ${ }^{4,5}$ Few studies have examined the long-term effects on terrorism survivors, although one large study found increases in PTSD between 3 and 5 years after the September 11 attacks., ${ }^{6,7}$ Risk factors included direct exposure (proximity, injury, witnessing horror), incidentrelated bereavement and low social support.

Bereavement that occurs in traumatic circumstances may have a considerable long-term impact on psychological distress and appears to slow the rate of recovery. ${ }^{8}$ Deaths involving deliberate violence are associated with higher prevalence of trauma conditions, depression and prolonged or "complicated" grief. 8,9 Complicated grief is characterised by continuing separation distress and bereavement-related traumatic distress. While frequently comorbid with depression or PTSD, it is increasingly recognised as a distinct condition that is associated with persistent functional impairments and negative health outcomes, particularly among those bereaved through terrorism. 9,10

The health and psychosocial effects of terrorism exposure have rarely been investigated beyond 3-4 years after such incidents. ${ }^{4,11}$ No studies have examined these effects among Australian survivors. Our aim was to examine the physical and mental health status of individuals directly affected by the 2002 Bali bombing, 8 years after the incident, and to deter-

\section{Abstract}

Objective: To examine the physical and mental health status of individuals directly affected by the 2002 Bali bombing, 8 years after the incident.

Design, setting and participants: Cross-sectional study of people directly exposed to and/or bereaved by the 2002 Bali bombing who had participated in a New South Wales Health therapeutic support program. Telephone interviews were conducted during July - November 2010. The sample was weighted to reflect the population of interest, registered participants in the program $(n=115)$.

Main outcome measures: Self-rated physical health, personal resilience (Connor-Davidson Resilience Scale), past-month psychological distress and daily functioning (Kessler Psychological Distress Scale), and traumatic stress-related symptoms (Primary Care PTSD Screen).

Results: Of 81 individuals contacted, 55 responded (68\%). Mean age of respondents was 50 years (range, 20-73 years), 32 were female, and seven were physically injured in the bombing. Most (45/55) reported good physical health, but 12 were experiencing high or very high levels of psychological distress. Being injured in the attack was associated with current functional impairment $(P=0.04)$ and very high levels of distress $(P=0.005)$. Lower distress was associated with perceived family support $(P=0.03)$ and being in a marital or de facto relationship $(P=0.02)$. Complicated grief factors were consistently associated with high psychological distress, traumatic stressrelated symptoms and lower personal resilience.

Conclusions: Eight years after the bombing, directly affected individuals had good physical health but relatively high rates of psychological distress. Marital or de facto relationships and perceived family support appear to be protective factors against long-term distress. Bereavement factors were the strongest correlates of trauma symptoms and distress. Outreach and screening programs incorporating complicated grief items may be useful in the longer-term support of such individuals.

mine demographic, exposure and loss-related correlates of these health outcomes.

\section{Methods}

Participants constituted a cross-sectional convenience sample of individuals who had experienced personal exposure and/or loss related to the 2002 Bali bombing and had current contact details listed with a New South Wales Ministry of Health therapeutic support program (Bali Recovery Program), where they had attended at least one consultation. Those who registered interest in response to a written invitation were contacted, given a description of the study, and asked for verbal consent. Professional interviewers from the NSW Health Survey Program completed computer-assisted telephone interviews between 9 July and 22 November 2010, excluding a period around the bombing anniversary (123 October). The validity of telephone-based interviews to assess stress and anxiety conditions has been demonstrated. ${ }^{12}$

\section{Measures}

We examined demographic and exposure factors to determine their relationship with physical and mental health outcomes. Exposure variables were: lifetime traumatic incident exposure, ${ }^{13}$ presence in Bali during/ after the bombing, involvement in the search for missing friends/relatives (first 48 hours), and bereavement circumstance (eg, multiple loss, family). Perceived social support from family and friends was assessed with two items from the Perceived Social Support Scale, ${ }^{14}$ as well as single items regarding neighbourhood social connectedness ${ }^{15}$ and overall support since the bombing.

Current bereavement experience ("experiential" grief) was measured using six items from the Inventory of Complicated Grief-Revised (ICG-R): separation distress (longing/yearning) and cognitive, affective or behavioural items (anger, acceptance, detach- 
1 Demographic, exposure and bereavement-related variables of the respondents

\begin{tabular}{|c|c|c|}
\hline Variable & $\begin{array}{c}\text { Unweighted } \\
(n=55)\end{array}$ & $\begin{array}{l}\text { Weighted } \\
(n=115)\end{array}$ \\
\hline Mean age (range) & $50(20-73)$ & $50(42-53)$ \\
\hline Male & $23(41.8 \%)$ & $48(41.8 \%)$ \\
\hline \multicolumn{3}{|l|}{ Education } \\
\hline University degree & $15(27.2 \%)$ & $31(27.3 \%)$ \\
\hline TAFE certificate or diploma & $17(30.9 \%)$ & $36(30.9 \%)$ \\
\hline Higher school certificate & $11(20.0 \%)$ & $23(20.0 \%)$ \\
\hline School certificate & $9(16.4 \%)$ & $19(16.4 \%)$ \\
\hline Other & $3(5.5 \%)$ & $6(5.5 \%)$ \\
\hline \multicolumn{3}{|l|}{ Marital status } \\
\hline Married or de facto & $40(72.7 \%)$ & $84(72.7 \%)$ \\
\hline Widowed & $3(5.5 \%)$ & $6(5.5 \%)$ \\
\hline Separated or divorced & $4(7.3 \%)$ & $8(7.3 \%)$ \\
\hline Never married & $8(14.5 \%)$ & $17(14.5 \%)$ \\
\hline \multicolumn{3}{|l|}{ Location during/after bombing } \\
\hline Bali, in club* & $6(10.9 \%)$ & $13(10.9 \%)$ \\
\hline Bali, near club* & $3(5.5 \%)$ & $6(5.5 \%)$ \\
\hline Bali, not nearby & $3(5.5 \%)$ & $6(5.5 \%)$ \\
\hline Bali, arrived after bombing & $9(16.4 \%)$ & $19(16.4 \%)$ \\
\hline Not in Bali & $34(61.8 \%)$ & $71(61.8 \%)$ \\
\hline \multicolumn{3}{|l|}{ Injured during bombing } \\
\hline No & $48(87.3 \%)$ & $100(87.3 \%)$ \\
\hline Yes & $7(12.7 \%)$ & $15(12.7 \%)$ \\
\hline \multicolumn{3}{|l|}{ Involved in search (first 48 hours) } \\
\hline No & $39(70.9 \%)$ & $84(72.7 \%)$ \\
\hline Yes & $16(29.1 \%)$ & $31(27.3 \%)$ \\
\hline \multicolumn{3}{|l|}{ Primary bereavement type $^{\dagger}$} \\
\hline Child & $21(38.2 \%)$ & $44(38.9 \%)$ \\
\hline Sibling & $11(20.0 \%)$ & $23(20.4 \%)$ \\
\hline Spouse & $3(5.5 \%)$ & $7(5.6 \%)$ \\
\hline Other family member & $4(7.3 \%)$ & $9(7.4 \%)$ \\
\hline Non-family member(s) & $15(27.3 \%)$ & $32(27.8 \%)$ \\
\hline \multicolumn{3}{|l|}{ Loss $^{\dagger}$} \\
\hline Single family member & $29(52.7 \%)$ & $61(53.7 \%)$ \\
\hline Multiple family members & $4(7.3 \%)$ & $9(7.4 \%)$ \\
\hline Multiple family and non-family & $6(10.9 \%)$ & $13(11.1 \%)$ \\
\hline Multiple non-family & $15(27.3 \%)$ & $32(27.8 \%)$ \\
\hline
\end{tabular}

TAFE $=$ technical and further education. * Bomb site.

†Bereaved respondents $(n=54)$.
Anxiety, depression, agitation, psychological fatigue and associated functional impairment (ie, full days unable to manage day-to-day activities due to symptom effects) in the past month were measured using the Kessler Psychological Distress Scale $(\mathrm{K} 10+)$. Individual scores range from 10 to 50 , indicating low (10-15), moderate (16-21), high (22-29) and very high (30-50) psychological distress. The latter is indicative of a significant mental health condition. ${ }^{18}$

We used the Primary Care PTSD Screen (PC-PTSD) to measure pastmonth traumatic stress-related symptoms (TSRS) specific to Bali-related experiences. Single items relate to one underlying characteristic specific to PTSD: re-experiencing, numbing, avoidance and hyper-arousal. The endorsement of 3-4 symptoms indicates "probable" PTSD and the need for specialist assessment. ${ }^{19}$

\section{Statistical analysis}

The dataset was weighted by age and sex to reflect registered participants in the Bali Recovery Program $(n=115)$. Current physical and mental health were analysed as outcome measures, with demographic, traumatic incident exposure, perceived support and bereavement factors used as independent variables.

Responses to the support and bereavement questions were expressed as dichotomous variables, with a value of 1 assigned to responses "agree" or "strongly agree", and 0 to "disagree", "strongly disagree" and "don't know". The outcome variables of physical health, personal resilience and functional loss were dichotomised into high and low (or good and poor) outcomes. Three outcome categories based on established clinical cut-offs were adopted for psychological distress (low-moderate, high and very high) and TSRS (low, moderate and high). ${ }^{18,19}$

Analyses were performed using Stata statistical software, version 12.0 (StataCorp), with "Svy" commands to allow for adjustments for sampling weight. We used the Taylor series linearisation method to determine prevalence estimates, and $\chi^{2}$ tests to test for significant differences in the prevalence of physical and mental health outcomes. Due to the relatively small sample size, an $\alpha$ significance level
$(P<0.15)$ was adopted, as it is a commonly used threshold for entry into multiple logistic regression analyses, ${ }^{20}$ and could provide indicative findings in the context of this exploratory study. Multiple testing using the Bonferroni correction was also carried out by dividing the target $\alpha$ level by the number of tests being performed. The significant adjusted $P$ values are reported.

\section{Ethics approval}

All study protocols were approved by the ethics committees of the Northern Sydney Local Health District and the University of Western Sydney (H7143).

\section{Results}

Of 81 individuals contacted, 55 agreed to participate $(68 \%$ of eligible respondents). The mean interval between the 2002 bombing and the interview was 7 years and 11 months (range, $7 \mathrm{y} 9 \mathrm{~m}-$ $8 \mathrm{y} 1 \mathrm{~m}$ ). There were no significant differences between the respondents and the total Bali Recovery Program population in terms of mean age $(P=0.38)$ or male sex $(P=0.39)$.

\section{Respondent characteristics}

Demographic, exposure and bereavement characteristics of the respondents are shown in Box 1. Of the 55 respondents, 21 were present in Bali during or shortly after the bombing. Almost three-quarters (39/54) experienced at least one family bereavement due to the bombing. The loss of children (of adult age) was predominant (21/54). Fifteen respondents experienced multiple losses of exclusively non-family members (average of seven friends and acquaintances killed).

\section{Physical health and personal resilience}

Physical and mental health prevalence estimates for the weighted sample are presented in Box 2 and Box 3. Good physical health in the past month and high personal resilience were reported by 45 and 30 of the 55 respondents, respectively. Respondents had an aggregate resilience score on the CD-RISC2 of 6.45. Poor selfrated health showed a significant relationship with current yearning for 
the deceased $(P=0.04)$ and perceived current difficulties moving on with life after the loss $(P=0.02)$. Experiential bereavement factors were the only variables associated with low personal resilience: current yearning $(P=0.02)$; perceived detachment from others $(P=0.04)$; life feeling empty without the deceased $(P=$ $0.02)$; and perceived difficulty moving on $(P=0.003)$.

\section{Psychological distress and daily functioning}

Current high and very high psychological distress was reported by seven and five respondents, respectively. High distress was significantly associated with difficulty accepting the loss $(P=0.03)$; feeling detached $(P=$ $0.001)$; and anger $(P=0.04)$. Very high distress was associated with bombing-related injury $(P=0.005)$; current yearning $(P=0.004)$; difficulty moving on $(P=0.003)$; and life feeling empty $(P<0.001)$. Very high distress also showed significant inverse relationships with current marital or de facto relationship $(P=0.02)$; perceived family support $(P=0.03)$; and better neighbourhood connectedness $(P=0.02)$. Loss of at least one full day of functioning in the past month was reported by nine respondents (range, 0-16 days; mean, 0.74). Significantly greater functional loss was associated with bombing-related injury $(P=$ $0.04)$ and not being in a current marital or de facto relationship $(P=0.04)$.

\section{Traumatic stress-related symptoms}

Moderate TSRS (two symptoms) and high TSRS (three or more symptoms) in the past month were reported by 11 and 15 respondents, respectively. High TSRS was positively associated with all assessed features of bereavement but no other outcome variables: current yearning $(P=0.007)$; difficulty accepting the loss $(P=0.005)$; feeling detached $(P=0.01)$; anger $(P=0.002)$; life feeling empty $(P=0.02)$; and difficulty moving on $(P<0.001)$.

\section{Comparisons with the NSW general population}

Compared with NSW population estimates, the respondents reported greater rates of high $(12.7 \% \mathrm{v} 8.2 \%)$ and very high $(9.1 \% \mathrm{v} 2.9 \%)$ psychological distress (Box 4) and functional

2 Prevalence estimates of individual health and wellbeing indicators in the weighted sample, by sociodemographic and perceived support factors

\begin{tabular}{|c|c|c|c|c|c|c|c|}
\hline Covariate & $\begin{array}{l}\text { Good self-rated } \\
\text { health }\end{array}$ & $\begin{array}{l}\text { High } \\
\text { resilience* }\end{array}$ & $\begin{array}{l}\text { Functional } \\
\text { loss }^{\dagger}\end{array}$ & $\begin{array}{l}\text { High } \\
\text { distress }^{\ddagger}\end{array}$ & $\begin{array}{l}\text { Very high } \\
\text { distress }\end{array}$ & $\begin{array}{l}\text { Moderate } \\
\text { TSRS }^{\delta}\end{array}$ & $\begin{array}{l}\text { High } \\
\text { TSRS }^{\delta}\end{array}$ \\
\hline \multicolumn{8}{|l|}{ Sex } \\
\hline Male & $78.3 \%$ & $60.9 \%$ & $17.4 \%$ & $8.7 \%$ & $4.3 \%$ & $13.0 \%$ & $21.7 \%$ \\
\hline Female & $84.4 \%$ & $53.1 \%$ & $15.6 \%$ & $15.6 \%$ & $12.5 \%$ & $25.0 \%$ & $34.4 \%$ \\
\hline \multicolumn{8}{|l|}{ Age } \\
\hline $18-40$ years & $73.3 \%$ & $57.9 \%$ & $26.3 \%$ & $10.5 \%$ & $10.5 \%$ & $26.3 \%$ & $26.3 \%$ \\
\hline$>40$ years & $86.1 \%$ & $55.6 \%$ & $11.1 \%$ & $13.9 \%$ & $8.3 \%$ & $16.7 \%$ & $30.6 \%$ \\
\hline \multicolumn{8}{|l|}{ Education } \\
\hline University & $86.7 \%$ & $66.7 \%$ & $20.0 \%$ & $13.3 \%$ & $6.7 \%$ & $20.0 \%$ & $26.7 \%$ \\
\hline High school/other & $80.0 \%$ & $52.5 \%$ & $15.0 \%$ & $12.5 \%$ & $10.0 \%$ & $20.0 \%$ & $30.0 \%$ \\
\hline \multicolumn{8}{|l|}{ Employed } \\
\hline No & $75.0 \%$ & $41.7 \%$ & $25.0 \%$ & $16.7 \%$ & $8.3 \%$ & $8.3 \%$ & $50.0 \%$ \\
\hline Yes & $83.7 \%$ & $60.5 \%$ & $14.0 \%$ & $11.6 \%$ & $9.3 \%$ & $23.3 \%$ & $23.3 \%$ \\
\hline \multicolumn{8}{|l|}{ Household income } \\
\hline$\leqslant \$ 60000$ & $77.8 \%$ & $44.4 \%$ & $27.8 \%$ & $22.2 \%$ & $11.1 \%$ & $16.7 \%$ & $22.2 \%$ \\
\hline$>\$ 60000$ & $82.9 \%$ & $62.9 \%$ & $11.4 \%$ & $8.6 \%$ & $5.7 \%$ & $20.0 \%$ & $31.4 \%$ \\
\hline \multicolumn{8}{|l|}{ Marital status } \\
\hline $\begin{array}{l}\text { Married or } \\
\text { partnered }\end{array}$ & $85.0 \%$ & $52.5 \%$ & $10.0 \%$ & $12.5 \%$ & $2.5 \%$ & $17.5 \%$ & $30.0 \%$ \\
\hline $\begin{array}{l}\text { Not married or } \\
\text { partnered }\end{array}$ & $73.3 \%$ & $66.7 \%$ & $33.0 \% * *$ & $13.3 \%$ & $26.7 \% * *$ & $26.7 \%$ & $26.7 \%$ \\
\hline \multicolumn{8}{|l|}{ Have children } \\
\hline No & $75.0 \%$ & $58.3 \%$ & $16.7 \%$ & $8.3 \%$ & $16.7 \%$ & $33.3 \%$ & $33.3 \%$ \\
\hline Yes & $83.7 \%$ & $55.8 \%$ & $16.3 \%$ & $14.0 \%$ & $7.0 \%$ & $16.3 \%$ & $27.9 \%$ \\
\hline \multicolumn{8}{|c|}{ Perceived support, family } \\
\hline Low & $80.0 \%$ & $60.0 \%$ & $20.0 \%$ & $20.0 \%$ & $40.0 \%$ & $40.0 \%$ & $20.0 \%$ \\
\hline High & $82.0 \%$ & $56.0 \%$ & $16.0 \%$ & $12.0 \%$ & $6.0 \% * *$ & $18.0 \%$ & $30.4 \%$ \\
\hline \multicolumn{8}{|c|}{ Perceived support, friends } \\
\hline Low & $85.7 \%$ & $42.9 \%$ & $14.3 \%$ & $14.3 \%$ & $14.3 \%$ & $0.0 \%$ & $42.9 \%$ \\
\hline High & $81.3 \%$ & $58.3 \%$ & $16.7 \%$ & $12.5 \%$ & $8.3 \%$ & $22.9 \%$ & $27.1 \%$ \\
\hline \multicolumn{8}{|c|}{ Social connections, neighbourhood } \\
\hline Low & $88.9 \%$ & $66.7 \%$ & $33.3 \%$ & $11.1 \%$ & $33.3 \%$ & $33.3 \%$ & $22.2 \%$ \\
\hline High & $80.4 \%$ & $54.3 \%$ & $13.0 \%$ & $13.0 \%$ & $4.3 \% * *$ & $17.4 \%$ & $30.0 \%$ \\
\hline \multicolumn{8}{|c|}{ Long-term support, all sources } \\
\hline Low & $75.0 \%$ & $75.0 \%$ & $0.0 \%$ & $25.0 \%$ & $12.5 \%$ & $0.0 \%$ & $37.5 \%$ \\
\hline High & $83.0 \%$ & $53.2 \%$ & $19.1 \%$ & $10.6 \%$ & $8.5 \%$ & $23.4 \%$ & $27.7 \%$ \\
\hline $\begin{array}{l}\text { Total } \\
\text { respondent group } \\
(95 \% \mathrm{Cl})\end{array}$ & $\begin{array}{c}81.8 \% \\
(68.9 \%- \\
90.1 \%)\end{array}$ & $\begin{array}{c}56.4 \% \\
(42.7 \%- \\
69.1 \%)\end{array}$ & $\begin{array}{l}16.4 \% \\
(8.6 \%- \\
29.0 \%)\end{array}$ & $\begin{array}{l}12.7 \% \\
(6.0 \%- \\
24.8 \%)\end{array}$ & $\begin{array}{c}9.1 \% \\
(3.7 \%- \\
20.5 \%)\end{array}$ & $\begin{array}{l}20.0 \% \\
(11.2 \%- \\
33.1 \%)\end{array}$ & $\begin{array}{c}29.1 \% \\
(18.4 \%- \\
42.8 \%)\end{array}$ \\
\hline
\end{tabular}

TSRS = traumatic stress-related symptoms. * Score of 7-8 on the short form of the Connor-Davidson Resilience Scale. $†$ Unable to complete usual activities on 1 or more days in previous month. ₹ Score of 22-29 on the Kessler Psychological Distress Scale indicates high psychological distress; 30-50 indicates very high distress. \$ Two symptoms on Primary Care PTSD Screen indicates moderate TSRS; $3-4$ symptoms indicates high TSRS. Я $P<0.15 . * * P<0.05$.

impairment (mean, $0.74 \mathrm{v} 0.60$ days lost in the past month). ${ }^{15}$ Respondents were significantly less likely to report low levels of psychological distress $(P<0.05)$. Good self-reported health was slightly higher among respondents than the population mean $(81.8 \%$ v $80.4 \%)$.

\section{Discussion}

Eight years after the first Bali bombing, a substantial proportion of this directly affected group were experiencing high levels of psychological distress and
TSRS. These individuals, who had sought help, were also experiencing near-normal physical health, and their aggregate resilience score fell within a "high resilience" range observed in United States population estimates. ${ }^{17}$ Although a specific comparison group is not available, access to modern treatment methods and support may have promoted these positive longterm outcomes. Notably, experiential features of grief (eg, emptiness, difficulty moving on) were the only factors associated with reduced resilience, suggesting that early intervention with 
3 Prevalence estimates of individual health and wellbeing indicators in the weighted sample, by incident exposure and bereavement factors

\begin{tabular}{|c|c|c|c|c|c|c|c|}
\hline Covariate & $\begin{array}{l}\text { Good } \\
\text { self-rated } \\
\text { health }\end{array}$ & $\begin{array}{l}\text { High } \\
\text { resilience* }\end{array}$ & $\begin{array}{c}\text { Functional } \\
\text { loss }^{\dagger}\end{array}$ & $\begin{array}{c}\text { High } \\
\text { distress }^{\ddagger}\end{array}$ & $\begin{array}{l}\text { Very high } \\
\text { distress }\end{array}$ & $\begin{array}{l}\text { Moderate } \\
\text { TSRS }^{5}\end{array}$ & $\begin{array}{l}\text { High } \\
\text { TSRS }^{\delta}\end{array}$ \\
\hline \multicolumn{8}{|l|}{ Lifetime exposure $^{\text {q }}$} \\
\hline Low & $84.0 \%$ & $60.0 \%$ & $16.0 \%$ & $16.0 \%$ & $4.0 \%$ & $32.0 \%$ & $32.0 \%$ \\
\hline High & $80.0 \%$ & $53.3 \%$ & $16.7 \%$ & $10.0 \%$ & $13.3 \%$ & $10.0 \%$ & $26.7 \% \neq \ddagger$ \\
\hline \multicolumn{8}{|c|}{ In Bali during or after bombing } \\
\hline No & $88.2 \%$ & $55.9 \%$ & $11.8 \%$ & $11.8 \%$ & $2.9 \%$ & $20.6 \%$ & $20.6 \%$ \\
\hline Yes & $71.4 \%$ 㧊 & $57.1 \%$ & $23.8 \%$ & $14.3 \%$ & $19.0 \%$ 㧊 & $19.0 \%$ & $42.9 \%$ \\
\hline \multicolumn{8}{|c|}{ Injured during bombing } \\
\hline No & $83.3 \%$ & $58.3 \%$ & $12.5 \%$ & $12.5 \%$ & $4.2 \%$ & $18.8 \%$ & $27.1 \%$ \\
\hline Yes & $71.4 \%$ & $42.9 \%$ & $42.9 \%$ & $14.3 \%$ & $42.9 \%$ & $28.6 \%$ & $42.9 \%$ \\
\hline \multicolumn{8}{|c|}{ Involved in search (first 48 hours) } \\
\hline No & $87.5 \%$ & $60.0 \%$ & $12.5 \%$ & $12.5 \%$ & $5.0 \%$ & $22.5 \%$ & $22.5 \%$ \\
\hline Yes & $66.7 \%$ 㧊 & $46.7 \%$ & $26.7 \%$ & $13.3 \%$ & $20.0 \%$ & $13.3 \%$ & $46.7 \%$ \\
\hline \multicolumn{8}{|l|}{ Bereavement** } \\
\hline $\begin{array}{l}\text { Non-family } \\
\text { member(s) }\end{array}$ & $80.0 \%$ & $46.7 \%$ & $20.0 \%$ & $13.3 \%$ & $13.3 \%$ & $20.0 \%$ & $40.0 \%$ \\
\hline Family member(s) & $84.6 \%$ & $61.5 \%$ & $12.8 \%$ & $10.3 \%$ & $7.7 \%$ & $20.5 \%$ & $23.1 \%$ \\
\hline \multicolumn{8}{|c|}{ Bereavement involved child**†† } \\
\hline No & $81.8 \%$ & $57.6 \%$ & $15.2 \%$ & $9.1 \%$ & $9.1 \%$ & $21.2 \%$ & $30.3 \%$ \\
\hline Yes & $85.7 \%$ & $57.1 \%$ & $14.3 \%$ & $14.3 \%$ & $9.5 \%$ & $19.0 \%$ & $23.8 \%$ \\
\hline \multicolumn{8}{|c|}{ Current yearning for loved one $(\mathrm{s}) * *$} \\
\hline No & $93.1 \%$ & $72.4 \%$ & $10.3 \%$ & $3.4 \%$ & $0.0 \%$ & $20.7 \%$ & $10.3 \%$ \\
\hline Yes & $72.0 \%{ }^{\$ \wp}$ & $40.0 \% \%^{\S \S}$ & $20.0 \%$ & $20.0 \%$ & $20.0 \% \%^{\S \S}$ & $20.0 \%$ & $48.0 \%{ }^{\$ 5}$ \\
\hline \multicolumn{8}{|c|}{ Difficulty accepting loss** } \\
\hline No & $90.6 \%$ & $62.5 \%$ & $15.6 \%$ & $3.1 \%$ & $6.3 \%$ & $18.8 \%$ & $12.5 \%$ \\
\hline Yes & $71.4 \%$ 㧊 & $47.6 \%$ & $14.3 \%$ & $23.8 \% \%^{\$ \$}$ & $14.3 \%$ & $19.0 \%$ & $52.4 \% \%^{\phi \xi}$ \\
\hline \multicolumn{8}{|c|}{ Feel detached from others** } \\
\hline No & $84.3 \%$ & $60.8 \%$ & $15.7 \%$ & $7.8 \%$ & $7.8 \%$ & $21.6 \%$ & $23.5 \%$ \\
\hline Yes & $66.7 \%$ & $0.0 \%$ & $0.0 \%$ & $66.7 \% \%^{\$ \varsigma}$ & $33.3 \%$ & $0.0 \%$ & $100.0 \% \%^{\phi \varsigma}$ \\
\hline \multicolumn{8}{|c|}{ Feel angry about loss** } \\
\hline No & $92.0 \%$ & $60.0 \%$ & $16.0 \%$ & $0.0 \%$ & $8.0 \%$ & $24.0 \%$ & $4.0 \%$ \\
\hline Yes & $75.9 \%$ 㧊 & $55.2 \%$ & $13.8 \%$ & $20.7 \% \%^{\S \xi}$ & $10.3 \%$ & $17.2 \%$ & $48.3 \% \%^{\phi \xi}$ \\
\hline \multicolumn{8}{|c|}{ Life feels empty without loved one(s)** } \\
\hline No & $86.4 \%$ & $65.9 \%$ & $11.4 \%$ & $6.8 \%$ & $2.3 \%$ & $22.7 \%$ & $20.5 \%$ \\
\hline Yes & $66.7 \%$ & $22.2 \% \%^{\S \S}$ & $22.2 \%$ & $33.3 \%$ & $33.3 \%$ яя & $11.1 \%$ & $66.7 \% \%^{\text {\$\$ }}$ \\
\hline \multicolumn{8}{|c|}{ Moving on remains difficult** } \\
\hline No & $87.5 \%$ & $64.6 \%$ & $12.5 \%$ & $8.3 \%$ & $6.2 \%$ & $22.9 \%$ & $18.8 \%$ \\
\hline Yes & $50.0 \%$ & $0.0 \%$ & $21.4 \%$ & $33.3 \%$ & $33.3 \%$ \$\$ & $0.0 \%$ & $100.0 \%$ १ด \\
\hline $\begin{array}{l}\text { Total } \\
\text { respondent group } \\
(95 \% \mathrm{Cl})\end{array}$ & $\begin{array}{c}81.8 \% \\
(68.9 \%- \\
90.1 \%)\end{array}$ & $\begin{array}{c}56.4 \% \\
(42.7 \%- \\
69.1 \%)\end{array}$ & $\begin{array}{l}16.4 \% \\
(8.6 \%- \\
29.0 \%)\end{array}$ & $\begin{array}{c}12.7 \% \\
(6.0 \%- \\
24.8 \%)\end{array}$ & $\begin{array}{r}9.1 \% \\
(3.7 \%- \\
20.5 \%)\end{array}$ & $\begin{array}{l}20.0 \% \\
(11.2 \%- \\
33.1 \%)\end{array}$ & $\begin{array}{l}29.1 \% \\
(18.4 \%- \\
42.8 \%)\end{array}$ \\
\hline
\end{tabular}

TSRS $=$ traumatic stress-related symptoms. $*$ Score of 7-8 on the short form of the Connor-Davidson Resilience Scale. + Unable to complete usual activities on 1 or more days in previous month. ₹ Score of 22-29 on the Kessler Psychological Distress Scale indicates high psychological distress; 30-50 indicates very high distress. $\oint$ Two symptoms on Primary Care PTSD Screen indicates moderate TSRS; $3-4$ symptoms indicates high TSRS. 9 Lifetime exposure to potentially traumatising events: low = 1-2 events; high $\geqslant 3$ events (excluding Bali exposure). ** Bereaved respondents $(n=54)$ ) $† \dagger$ Non-dependent child. $\neq \neq P<0.15$. $\$ \$ P<0.05$. จด् $P<0.001$ (Bonferroni adjusted).

a specific focus on these factors may be indicated for such groups. ${ }^{10}$

Direct exposure to disasters is considered to have a dose-response effect. Factors such as proximity, injury and perceived threat to life are consistently associated with adverse mental health effects, but they are rarely examined beyond 3-4 years after terrorism incidents because of difficulty accessing affected cohorts. ${ }^{11}$ Eight years after the Bali bombing, a significant association was observed between incidentrelated physical injury and both psychological distress and functional impairment. These findings extend the current literature, showing that some of the most direct forms of exposure (proximity and injury) remain substantial risk factors at this extended time point.

Social support has a positive role in mental health and may foster recovery from trauma over time. ${ }^{21}$ We found that being in a marital or de facto relationship was the only demographic factor associated with distress in the respondent group, showing an inverse relationship with high psychological distress. Inverse relationships were also observed with the broader social support factors of high perceived family support and neighbourhood social connectedness.

The strength of our findings in relation to complicated grief variables appears to highlight important aspects of grief, as it relates to terrorism violence and loss. The ability to "make sense" of a loved one's death is considered a central process of grieving. ${ }^{8}$ However, the irrational or meaningless nature of violent death, particularly through terrorism, has been found to interfere with this cognitive process for many survivors. ${ }^{22}$ Moreover, it is associated with more severe complicated grief, higher psychological distress and poorer physical health. ${ }^{23}$ While such mediating variables cannot be inferred in relation to our data, it is notable that complicated grief symptoms in this study were also associated with distress and poor physical health, as well as TSRS. Similarly, grief symptoms were also the only factors associated with significantly lower personal resilience. This suggests that among bereaved survivors of terrorism, grief maladaptation may represent a more significant long-term risk factor for health outcomes than incident exposure or post-event variables.

Our findings have implications for the support of people directly affected by terrorism. Complicated grief factors emerged as the strongest correlates of adverse physical and mental health status. Longer-term monitoring of survivor groups is indicated, including screening programs that incorporate grief-specific items. Previous shortterm screening has effectively linked survivors with evidence-based care. ${ }^{10,24}$ However, case-finding from primary care pathways was poor, suggesting that outreach is required for longer-term initiatives. ${ }^{24}$ Significantly, 7 years after the September 11 attacks, registered individuals who had 


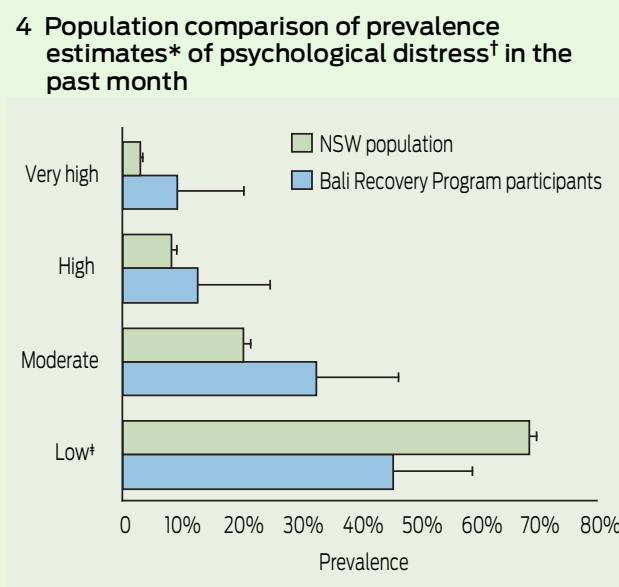

*Bali Recovery Program 2010 weighted sample and New South Wales population weighted prevalence estimates (2010). ${ }^{15}$ † Measured using the Kessler Psychological Distress Scale. $\ddagger P<0.05$.

escaped the World Trade Center reported difficulty accessing physical and mental health care and often failed to connect long-term symptoms with their September 11 exposures. ${ }^{25}$

Our study has some notable strengths and several limitations. The sample ostensibly constitutes a traumatically bereaved population, with varying levels of direct incident exposure and use of clinical services. Respondents may represent a more seriously affected, but possibly better supported cohort than those who did not seek services from the program. This may limit generalisability of these findings to other survivor groups. This cross-sectional study can only determine significant associations at a single time point. No conclusions can be drawn regarding longitudinal health effects or their causes.

The response rate had the potential to introduce responder bias, although no significant differences in sex or age were found between the respondent sample and the total program population. Items from the complicated grief measure (ICG-R) examined a subset of symptoms only and cannot be considered to indicate syndromelevel complicated grief.

Importantly, this analysis presents the largest study sample to date of Australians directly affected by a single terrorist incident. In completing a quantitative analysis of their health status 8 years after a major bombing, it also represents, to our knowledge, the longest follow-up period of a terrorism-affected population reported in the literature.

Acknowledgements: This study was funded by the Australian Research Council (project no. DP0881463). This analysis is part of Garry Stevens' thesis for a doctoral dissertation with the School of Medicine at the University of Western Sydney. Our thanks to the Health Survey Program interviewers at the Centre for Epidemiology and Evidence, NSW Ministry of Health.

\section{Competing interests: No relevant disclosures.}

Received 2 Oct 2012, accepted 7 Feb 2013.

1 National Consortium for the Study of Terrorism and Responses to Terrorism (START). Global Terrorism Database. http://www.start. umd.edu/gtd (accessed Sep 2012).
2 Hampson GV, Cook SP, Frederiksen SR. Operation Bali Assist. Med J Aust 2002; 177: 620-623.

3 Rosenfeld JV, Fitzgerald M, Kossmann T, et al. Is the Australian hospital system adequately prepared for terrorism? Med J Aust 2005; 183: 567-570.

4 Neria Y, DiGrande L, Adams BG. Posttraumatic stress disorder following the September 11,2001, terrorist attacks: a review of the literature among highly exposed populations. Am Psychol 2011; 66: 429-446.

5 Perlman SE, Friedman S, Galea S, et al. Short-term and mediumterm health effects of 9/11. Lancet 2011; 378: 925-934.

6 Brackbill RM, Hadler JL, DiGrande L, et al. Asthma and posttraumatic stress symptoms 5 to 6 years following exposure to the World Trade Center terrorist attack. JAMA 2009; 302: 502-516.

7 DiGrande L, Neria Y, Brackbill RM, et al. Long-term posttraumatic stress symptoms among 3,271 civilian survivors of the September 11, 2001, terrorist attacks on the World Trade Center. Am J Epidemiol 2011; 173: 271-281.

8 Currier JM, Holland JM, Neimeyer RA. Sense-making, grief, and the experience of violent loss: toward a mediational model. Death Stud 2006; 30: 403-428.

9 Nakajima S, Ito M, Shirai A, Konishi T.Complicated grief in those bereaved by violent death: the effects of post-traumatic stress disorder on complicated grief. Dialogues Clin Neurosci 2012; 14: 210-214.

10 Shear K, Jackson C, Essock S, et al. Screening for complicated grief among Project Liberty service recipients 18 months after September 11, 2001. Psychiatr Serv 2006; 57: 1291-1297.

11 Tucker PM, Pfefferbaum B, North CS, et al. Physiologic reactivity despite emotional resilience several years after direct exposure to terrorism. Am J Psychiatry 2007; 164: 230-235.

12 Rohde P, Lewinsohn PM, Seeley JR. Comparability of telephone and face-to-face interviews in assessing axis I and axis II disorders. Am J Psychiatry 1997; 154: 1593-1598.

13 Australian Bureau of Statistics. National Survey of Mental Health and Wellbeing: user's guide, 2007. Canberra: ABS, 2009. (ABS Cat. No. 4327.0.) http://www.abs.gov.au/ausstats/abs@.nst/mf/ 4326.0 (accessed Sep 2012)

14 Procidano ME, Heller K. Measures of perceived social support from friends and from family: three validation studies. Am J Community Psychol 1983; 11: 1-24.

15 Centre for Epidemiology and Research. 2010 Report on adult health from the New South Wales Population Health Survey. Sydney: NSW Department of Health, 2011. http://www.health. nsw.gov.au/publichealth/surveys/hsa/10pub.asp (accessed Sep 2012).

16 Prigerson HG, Bierhals AJ, KasI SV, et al. Complicated grief as a distinct disorder from bereavement-related depression and anxiety: a replication study. Am J Psychiatry 1996; 153: 1484-1486.

17 Vaishnavi S, Connor K, Davidson J. An abbreviated version of the Connor-Davidson Resilience Scale (CD-RISC), the CDRISC2: psychometric properties and applications in psychopharmacological trials. Psychiatry Res 2007; 152: 293-297.

18 Andrews G, Slade T. Interpreting scores on the Kessler Psychological Distress Scale (K10). Aust N Z J Public Health 2001; 25: 494-497.

19 Prins A, Ouimette $P$, Kimerling R, et al. The primary care PTSD screen (PC-PTSD): development and operating characteristics. Prim Care Psychiatr 2003; 9: 9-14. http://www.ptsd.va.gov/ professional/articles/article-pdf/id26676.pdf (accessed Sep 2012).

20 Verger P, Dab W, Lamping DL, et al. The psychological impact of terrorism: an epidemiologic study of posttraumatic stress disorder and associated factors in victims of the 1995-1996 bombings in France. Am J Psychiatr 2004; 161: 1384-1389.

21 Koenen KC Stellman JM, Stellman SD, Sommer JF Jr. Risk factors for course of posttraumatic stress disorder among Vietnam veterans: a 14-year follow-up of American Legionnaires. J Consult Clin Psychol 2003; 71: 980-986.

22 Davis CG, Wortman CB, Lehman DR, Silver RC. Searching for meaning in loss: are clinical assumptions correct? Death Stud 2000: $24:$ 497-540.

23 Murphy SA, Braun T, Tillery L, et al. PTSD among bereaved parents following the violent deaths of their 12- to 28-year-old children a longitudinal prospective analysis. J Trauma Stress 1999; 12 . 273-291.

24 Brewin CR, Fuchkan N, Huntley Z, et al. Outreach and screening following the 2005 London bombings: usage and outcomes. Psychol Med 2010; 40: 2049-2057.

25 World Trade Center Medical Working Group of New York City. 2008 Annual Report on 9/11 Health. WTC Medical Working Group of New York City: New York, 2008 http://www.nyc.gov/html/om/pdf/ 2008/2008_mwg_annual_report.pdf (accessed Sep 2012). 